\title{
Achieving competitive advantage through the integration of disabled architects in architectural design firms in Egypt
}

DOI 10.1515/otmcj-2016-0017

Received September 6, 2016; accepted May 15, 2017

Abstract: The 2030 strategy of sustainable development in Egypt is based on integrated goals, including Human Resource Development. Egypt has 9,540 disabled architects, who can play an important role in achieving competitive advantage through their integration in Architectural Design Firms (ADFs). By neglecting the benefits of integrating disabled architects, ADFs encounter the risk of losing unique skills and competent personnel. This article investigates the integration of disabled architects in ADFs as an approach for achieving competitive advantage. To achieve this aim, a research methodology consisting of literature review, case studies, and survey questionnaire has been adopted, and it is designed to achieve five objectives. First, literature review is used to investigate the concepts of disabilities and competitive advantage, as well as the relation between integrating disabled architects and the achievement of competitiveness in ADFs. Second, six case studies are presented and analyzed to investigate the role and process of achieving competitive advantage in ADFs through employing disabled architects. Third, the results of a survey questionnaire are analyzed to examine the perception regarding and application of employing disabled architects as an approach for achieving competitive advantage in ADFs in Egypt. Fourth, a framework is developed to facilitate the integration of disabled architects in ADFs with the goal of achieving competitive advantage. Finally, the research findings are summarized and recommendations are put forth. The value of this research stems from the need to address the issue of lack of employment of disabled architects in ADFs and the benefits of making better use of their unique capabilities and skills toward

\footnotetext{
*Corresponding author: Ayman Ahmed Ezzat Othman, Architectural Engineering Department, The British University in Egypt, Cairo, Egypt, Email: ayman.othman@bue.edu.eg

Marise Hossam Hosny Sorial, Architectural Engineering Department, The British University in Egypt, Cairo, Egypt
}

achieving competitiveness. In addition, this research covers a controversial topic that receives scant attention in construction literature, especially in Egypt.

Keywords: architectural design firms, competitive advantage, disabled architects, diversity, employment, Egypt

\section{Research background and rationale}

Currently, Egypt is witnessing an economic recovery after 4 years of slow activity. The "Sustainable Development Strategy: Egypt Vision 2030" agenda identified four main goals of sustainable development, namely, Economic Development, Market Competitiveness, Citizens' Happiness, and Human Development (Ministry of Planning 2016). For this envisioned improvement and development to take place and proceed, there is no place for wasting Egyptian resources. Egypt's main wealth is its human resources, but why are there whole categories of these resources being completely underestimated or marginalized?. According to the Egyptian Engineers Syndicate, Egypt has 9,540 disabled architects who have different disability conditions and most of them are qualified, yet unemployed (Egyptian Engineers Syndicate 2015). Failure to utilize these valuable resources affects the achievement of the national sustainable development agenda and the competiveness of ADFs. Accordingly, this article aims to investigate the role of integrating disabled architects in ADFs as an approach for achieving competitive advantage. Although the number of disabled architects in Egypt should not be neglected, this issue was never previously addressed in Egypt before. On the other hand, the employment of disabled can be an innovative method of achieving competitive advantage because of the different capabilities it offers, including diversity, wide talent pool, 
tax benefits, improved image, and legal issues (Joseph 2015).

\section{Research objectives and methodology}

In order to achieve the aforementioned aim, a research methodology that consisted of literature review, case studies, and survey questionnaire has been designed to achieve five objectives.

- First, literature review is used to build a comprehensive background about the research topic by investigating disabilities in terms of its multiple types, capabilities of the disabled, employment barriers, codes and regulations for employment of the disabled in Egypt, competitive advantage, and the relation between integrating disabled architects and the achievement of competitiveness.

- Second, six case studies of two types, namely, (i) individual disabled architects and (ii) companies that hire disabled architects, are presented and analyzed to investigate the role played by disabled architects in gaining competitive advantage for themselves and their companies.

- Third, the results of a survey questionnaire, conducted by the authors with a representative sample of ADFs in Egypt, are presented and analyzed to examine the perception regarding and application of employing disabled architects as an approach for achieving competitive advantage in ADFs.

- Fourth, a framework has been developed to facilitate the integration of disabled architects as an approach toward achieving competitive advantage in ADFs.

- Finally, the research findings are outlined and recommendations useful for ADFs are put forth.

\section{Literature review}

\subsection{Disability}

\subsubsection{Disability and its different types}

The word "disability" is defined as the consequence of any impairment that happens to a person, resembling the term disability as an umbrella word that covers different aspects of disabilities (WHO 2014). The word "disability" is better represented as a culture wherein there is an enormous range of varieties and differences among the persons living in it, and the community must be capable of accommodating their differences. On the other hand, the community defines disability as the lack of adequate power, mental ability, physical ability, strength or capacity to lead a normal full life, facing disadvantages in terms of disqualification and lack of insurance (Brown 2002). Furthermore, Barnartt (2010), in her book "Disability as a Fluid State" agrees with Brown, by describing that disability is not impairment but a relation with impairment. She complains about the common belief that a disability is a permanent condition that classifies the disabled (Barnartt 2010). Crow agrees with Barnartt, scientifically presenting the different cases of disabilities underlying the main three disability umbrellas, which are impairment, activity limitations, and participation restrictions; the disabilities were subcategorized into physical disability, sensory disability, intellectual disability, emotional disability, pervasive development disability and developmental disability. Figure 1 shows the different types of disabilities (Crow 2008).

\subsubsection{Capabilities of the disabled}

Mitra (2006), in her article "Capability Approach and Disability", states that there are three main components for the approach to capability. This approach allows researchers to analyze (1) the actual disability, (2) potential disability at the level of functioning, and (3) disability at the level of capability. This framework also explains how a disability can be a result of three different factors, namely, (1) the personal individual characteristics (e.g., age, gender, race, impairment), (2) the environment of the individual, and (3) the resources of the individual (Mitra 2006). The capability approach is explained as an analysis framework used to analyze the different concepts of welfare economics. It includes the standard of living, the quality

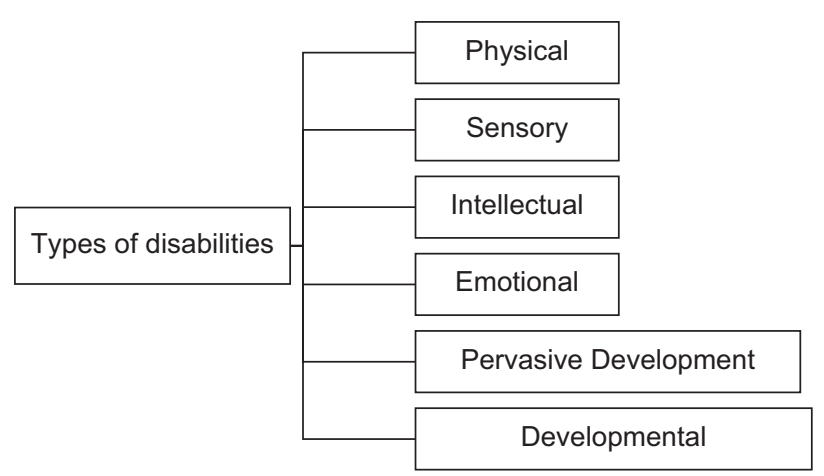

Fig. 1: Types of disabilities (Crow 2008). 
of life, poverty, and personal well-being. He claimed that the standards of living can be measured by how much a disabled person can afford a commodities basket, or in terms of utilities or tools, where utilities mean happiness, pleasure, and satisfaction and tools refer to choice and valuation. Mitra focuses, under the approach of capability, on the fact that disabled people have the ability to live according to their achieving and accomplishing capabilities of doing and being what they can do best. In addition, he considered that the commodities basket can only be valuable to a certain extent when it gives the person an opportunity to be or do multiple things. A person can only be disabled if his/her ability to do his/her job or perform his/her tasks is limited. The focus on the person with impairment of work performance, or work functioning, is convenient as work is considered an observable value on which the assessment of the value of person's disability can be based (Sen 2005).

\subsubsection{Disabled in Egypt}

The issue of disabled Egyptians is a multifaceted issue, which negatively affects not only the disabled persons themselves but also other segments in the society. For example, when the household becomes disabled, the kids are forced to leave their schools and start working to get an income. On the other hand, disabled workers' rights of compensation are very limited and mainly not enforced, as disabled in Egypt are stigmatized and not encouraged nor used as active useful members of the society who can provide a competitive advantage if given suitable job opportunities. This marginalization and other cultural norms have urged many families in Egypt to hide their disabled members from the society, which gives disabled persons the feeling that society rejects them and their existence is not desired (Elshami 2012).

\subsubsection{Disabled architects in Egypt}

Unemployed disabled architects in Egypt constitute a serious, crucial problem facing Egypt's waste of human and mental resources not only in the engineering firms but in all the fields. The percentage of disabled persons in Egypt ranges between $10 \%$ and $12 \%$, a percentage not to be neglected. On the other hand, within the $12 \%$ disabled population in Egypt, there are 3\% with educational degrees that allow them to have an appropriate career. According to the Egyptian Engineers Syndicate (2015), the average number of engineers in Egypt is $~ 530,000$, of which 63,600 are disabled engineers in different specialties. The percentage of architects graduating each year ranges between $13 \%$ and $15 \%$, yielding a final average number of disabled architects in Egypt of 9,540 (El Sayed 2013). According to the organizational practice regulations list, the rules do not prohibit any disabled architect from having an appropriate career in ADFs. The laws and conditions only concern different aspects such as professional details, e.g., the minimum salary, and other ethical aspects regarding respecting the occupation and performing the needed task on time (Egyptian Engineers Syndicate 2015). Moreover, the Rehabilitation of Disabled Persons Law, established in 1975, gives the disabled person the right of trainings and employments. The governmental policies for disabled Egyptian employment are based on a quota, which is not enforced, yet obligates every company with $>50$ employees to have $5 \%$ disabled employees among its total employees (Elshami 2012).

\subsubsection{Barriers to disabled architects' employment}

- Performance of the disabled on construction sites: Disabled architects meet extra obstacles and difficulties in visiting their project sites, which is a fundamental process, starting from conducting the architectural design of the project and even after the design is completed, for supervisions and monitoring the workers.

- Accommodations: It was found that the main drawback was not only the cost of the accommodations but the lack of needed awareness regarding handling the disabled architects' needs in their accommodations, with the employers tending to have negative perceptions in both regards, namely, the need for accommodations and the cost of accommodations.

- Employers' attitude: The employers show their sympathy toward the disabled architects, although the former do not show sympathy toward employing the latter.

- Increased cost: Not only cost of accommodations but also other expenses were a frequently encountered barrier in employing disabled architect in the opinion of the employers. The fact is that small-sized and medium-sized companies, according to their basic concerns, are losing a great deal of their revenue in the needed trainings. On the other hand, large-sized companies do not take into consideration the issue of disabled architects' training costs.

- Customer satisfaction: The unemployment of the disabled architects was not only based on the lack of desire 
to employ them but also on the beliefs of the customers that disabled architects may not function effectively or be qualified for doing their projects. On the other hand, the employers claimed that the customers may feel marginalized or underestimated by the employers when their projects are covered by a disabled architect and consider it as a method of humiliation not considering that the disabled architect could be more qualified and skilled than the able one, resulting in losing customers, which is totally undesirable.

- Coworkers' attitude: In the medium-sized companies, the barrier of coworkers' attitude is more powerful, as teamwork is applied more than individual work.

- Managing workers: The employers consider that disabled architects should be treated or managed in a different manner whether concerning disciplining, motivation or scheduling the tasks.

- Low comfort level: The employers and coworkers rate the level of comfort of working with disabled architects to be very low compared to the level of comfort needed in a teamwork.

- Discrimination and bias: Discrimination and bias contribute to decreasing the rates of employment of disabled architects, as well as the employers' desire to employ them (Kaye et al. 2011).

\subsection{Competitive advantage}

\subsubsection{Definition and background}

Competitive advantage is defined as the advantage gained over competitors when the company offers the customers greater value, either by offering the customers additional services and benefits at the same prices or offering them lower prices and the same services and benefits. For producers and growers involved in marketing, nurturing and finding a competitive advantage means the increase in the profit and the venture that is successful in the long run and sustainable. In Porter's summary of competitive advantage, he suggested some generic strategies to be adopted to achieve competitiveness in the company, related to the scope of the business' activities and the differentiation in focus (Ehmke 2008). Riley explained Porter's main generic strategies, which are cost leadership, cost focus, differentiation leadership and differentiation focus. The cost leadership and differentiation leadership strategies involve seeking competiveness in a broad range; on the other hand, cost focus and differentiation focus seek competitiveness on a narrower scale (Riley 2015).

\subsubsection{Competitiveness and disabled employees' integration}

One of the methods for achieving competitive advantage is "workplace diversity". Diversity simply means difference or variety, which means that for a company to be successful, the presence of diversity among its employees is fundamental. Diversity in companies causes additional success in multiple ways. First, in production, the differences between employees in the workplace creates a competition, which forces the architects to be pushed beyond their normal limits, resulting in better and increased products, on both levels, the individual and the team. The competition between the employees can be enforced and motivated through different methods of rewarding. Second is self-improvement. To get the competition going, bonuses and financial motivations are always a positive issue, but the architects, who can see the larger picture, take the competitions as opportunities to help them get better in the winning of the competition; in other words, these architects use the competition not only to get a reward but to improve their skills, experience, and capabilities in performing tasks. Third is the teamwork. In most of the architectural companies, teamwork is involved in improvization of the products, so competitions are not necessarily individual competitions but also on the team level. Competitions can be more effective and create a sense of teamwork where all the architects have to work together to produce a better result and get evaluated as a group, which motivates them to help each other for the favorable result in terms of the final production (Sharaf and Othman 2015).

\section{Case studies}

This section presents and analyzes six case studies divided into two types. The first type encompasses three case studies of disabled architects who succeeded not only in doing what other architects can achieve, but in outdistancing the latter and exceeding their achievements. The second type invloves three cases of companies that hired disabled employees to increase their competitive advantage. The names and references of these companies are not mentioned to focus on the target of learning from these case studies instead of going through an unintended marketing process. However, this information can be obtained from the authors upon request. 


\subsection{Karen L. Braitmayer}

Braitmayer has been able to offer a unique combination of professional expertise as she is a registered architect and has personal experience in being a user of the wheelchair since her birth. On the other hand, Braitmayer has been able to prove the advantage that any company could get on employing her. She has worked with private organizations and civic organizations and she is completely committed to complying with the state codes and the federal laws. Braitmayer, who is considered a disabled architect, could achieve customers' satisfaction in her designs by respecting the diversity of the users even more than other architects. She was able to create spaces that are optimally usable with the largest range of individual variation for users. Braitmayer was considered an advantage not only in terms of the design and her respect for diversity, but also because she won several awards for her contributions in numerous boards and committees. Braitmayer proceeded with her series of successful achievements through being a resource for state, local, and federal government officials; she also advocates for the disabled architects and their rights across the country and in her region after being elevated by the American Institute of Architects to the College of Fellows, one of the highest honors of the profession. Braitmayer participated in developing the standards and codes that ensure that the needs of Washington's citizens are reflected and respected through these codes since 1989. The disabled successful architect was also appointed as a member of the Washington State Building Code Council, as a representative for persons with disabilities since 1994 and until 2001. Braitmayer was not only considered a success or a competitive advantage to the organizations she worked for but also a pride to her country. In September 2010, Ms. Braitmayer was appointed by President Obama to the US Access Board, which is an independent subsidiary federal agency that provides accessible design leadership under many laws, including the Americans with Disabilities Act. Braitmayer is not only designing projects but also providing consultation for a huge number of community development projects. Braitmayer believes that her impairment is the unique perspective that shaped her career as an architect (Olson 2004).

\subsection{Christopher Downey}

Christopher Downey is an architect, consultant, and planner. In 2008, Downey lost his sight completely. Since that time, he became dedicated to making more friendly, enriching, and helpful environments for the visually impaired and the blind. Downey consults on the designs made especially for the blind people, encompassing facilities that serve the public as well as specialized centers. Downey's work ranges from the renovation of houses for people with visual impairments, to the new Transbay transit center in the city of San Francisco and the new department in the blinds' rehabilitation center. Christopher, being one of the very few blind architects in the world who practice his profession, has been an image and a privilege for any company he has worked with/for. Downey has been featured in both national and international media; he speaks regularly about visual impairment, architecture, and the complicated link between both. Downey not only works as an architect, but he also teaches universal design and accessibility at University of California, Berkeley. Moreover, he serves on the directors' board for the Blind's Lighthouse in the city of San Francisco. Downey uses his unique perspective in facilitating the integration of some critical tools for the blind in his designs, as well as providing greater clarity for the project as a whole. He considers thoroughly the touch, smell, temperature, sound, and tactility features, as well as new technologies to be able to provide his design with unique characteristics that make life easier for diverse users. Christopher also helps in crafting a design process that is more responsive to the needs of both end users and blind clients. Furthermore, Christopher believes that great architecture for the visually impaired and blind is similar to other great architecture, but only better. The architecture that respects humans' diversity looks like any other architecture but offers a better and richer respect to the needs and involvement of all the senses. Christopher offers the potential of enhancing the experience in any environment that serves a greater proportion of humans (Prato 2013).

\subsection{Olof Hanson}

Olof Hanson was born in Sweden. His father was a farmer, railroad director, and country official. In 1874, his family had made arrangements to travel to America after selling their farm. The trip was postponed due to the passing of the father. After a year, the family settled near Minnesota (MN). After 2 weeks, Hanson lost his hearing. Olof used to attend public schools in Sweden before becoming deaf. In 1878, he started to attend a school for the deaf at Faribault, MN, USA, where he graduated in 1881. Afterward, Olof entered the College of Gallaudet at Washington, DC, USA, from where he graduated in 1886 . He graduated 
with honors as the head of the largest class at the college at that time. After his graduation, Olof entered the offices of Hodgson and Son for architects in Minneapolis, MN. He remained in the firm until 1889, until he had to travel to Europe for his professional study. He spent 10 months visiting Norway, Sweden, Denmark, Germany, Switzerland, Italy, France, Scotland, and England. He returned back in 1890 to start his career with Wilson Bros and Co. in Philadelphia (PA); he was engaged for a year on the plans for a new project, which was a new school for the deaf in Pennsylvania at Mt. Airy, PA. In 1891, Olof returned back to MN to work as an architect in Duluth. He spent the next couple of years teaching at Faribault in a school for the deaf. However, Olof was fonder of his architectural profession than teaching. Therefore, he started his own architectural office in Faribault. Olof, through his career, participated in many different projects, such as Dr. J. L. Noyes residences, state school building at Faribault for the feeble-minded, including a dormitory building for boys at Kendall school, a school for the deaf at North Dakota, six stores, business blocks, a hotel in Venezuela for the Orinoco Company, and six other projects in Faribault and different places. Furthermore, he was engaged in the public school in Faribault, which was the winning building among 20 other works of architects in a competition. Most of Olof's papers were donated to Gallaudet University archives. While some of them can be found in Faribault, MN, at the Rice County Historical Society, the remainder of his papers are located in the University of Minnesota. The Department for the Special Collections at the University of Washington has a collection of Olof's materials, which are related to his work in the University. Finally, Hanson was the president of the National Association of the Deaf in the United States for 3 years. Hanson was considered a catch for any company or firm he worked with/for. He was the reason for creating a space for diversity in any company he worked in, which was reflected in the way he was always chosen for some unique projects that required a unique talent and experience. Hanson was the pride of all the organizations he was involved with, which made each organization keep a part of his materials as a source of pride. On the other hand, Hanson's wide knowledge, which required mobility, did not hinder him from finding new job opportunities in different places. His disability became an advantage and a special feature in his career rather than being an impairment. Hanson was able to be an opportunity for the companies he worked for to achieve competitive advantage. He was a living evidence that a disabled architect is only an architect with an impairment who did not get the opportunity he needs (Graham 2014).

\subsection{Company one}

This Company considers providing equal opportunities to the disabled as a law and legal right. Their first concern regarding rejecting disabled employees is facing legal issues. On the other hand, the company provides an environment that respects disabled employees and gives them equal opportunities. The company follows the law in employing the disabled according to the quota for employment of the disabled and protects them from the discrimination they may face during hiring, classification, training, benefits, payment, discharge and other employment aspects. The company also considers the unreasonable accommodation for the employees' mental or physical limitations as a disability-based discrimination. Moreover, the company considers it fundamental to protect their rights through a written contract between the two sides. On the other hand, the company believes in the importance of the presence of disabled employees in a company that provides products and supplies to $90 \%$ of the Egyptian families, any of which may contain a disabled person among it members. The company believes in using the same mentality of the user to be able to design for them the most suitable products, which means that the company must include employees from all the categories of humans that it serves. In other words, the company believes in the importance of the diversity in its products as it offers products that are fundamental in all the houses. In conclusion, the company believes in achieving competitive advantage through the integration of disabled employees based on diversity and avoidance of legal issues.

\subsection{Company two}

The second company is creating a strong culture within the company, including engaging and developing all its employees. The company's inclusive culture gives the chance to any person to work in a high-performance environment, which makes the company's employees recognizable in any place. Moreover, speaking of the potential employers, the organization's culture is inclusive to everyone, including disabled employees. It believes in achieving diversity through recruiting and hiring employees from different cultures, backgrounds, sexual orientations, ethnicities, abilities, and disabilities. Furthermore, the company values the differences and believes that differences help in creating and delivering better business results and achieving competitiveness within the company. The company gives a wide range of opportunities for different people in the same room, which produces a wider range of products and ideas. 
According to the company's representative, the company's goal is not only the success of its people, but also their promotion within the company itself; all the disabled employees are considered among the companies' people. The representative proceeds that the jobseekers need to check how their prospective employers are friendly to people with disabilities and how the employer can offer the needed support for the disabled to develop and be promoted in his/ her career. The representative discussed how the company perceives its disabled employees as its method of achieving success and competitiveness. The Company makes sure that all the disabled employees receive the needed accommodations and facilities to be able to offer their best for the company and for their own career. Furthermore, the representative added, the disabled applicant must be provided the needed facilities and accommodation through interview to be able to perform in a comfortable environment like the others. Moreover, the company focuses on establishing strong relationships between the disabled employees and his/her coworkers so that they can get the support they need to feel appreciated in the company. Its success is based on diversity, which leads to competitiveness; it works on providing the disabled employees with all that they need, ranging from opportunities to accommodations, facilities, and support, so that they can offer all they have. In conclusion, the company believes in achieving competitive advantage through integrating disabled employees, based on diversity.

\subsection{Company three}

The company's commitment to inclusion and diversity is considered a daily priority. At the company, it is strongly believed that the talents come in every expert status, sexual orientation, religion, origin, gender, color, and physical capabilities. For this reason, the company seeks out vendors, business associates, and employees from deeper and more diverse pool of professionals, aiming to build a better image and a respected name in the industry of finance. Moreover, it strives to develop, inform, support, and increase the sensitivity and awareness of its current workforce, aiming to create a better environment for its disabled employees. Moreover, the company encourages the activities that are open to the disabled employees that help in their development and growth. It encourages all the qualified and interested candidates to apply for the available job opportunities regardless of their disability, assuring them that they will get all the facilities and trainings they need to perform their tasks. The company depends on employing disabled employees to achieve competitive advantage. The company believes in their power of providing the company with better image, strong name, and wider diverse pool of talent. Finally, it provides its disabled employees with all the facilities and trainings they need, aiming to develop their talents and experiences, in addition to improving the attitude of their coworkers toward them. In conclusion, the company believes in achieving competitive advantage through disabled employees' integration based on diversity and improved image.

\subsection{Summary of findings and discussion}

This section included six different case studies; three of them presented different disabled architects with different circumstances, careers, and achievements, reflecting the disabled people's capability for achieving competitiveness. The last three cases presented three companies, aiming to show the relation between providing the needed facilities and achieving competitiveness through employing disabled architects. Through a comparison of the first three case studies, we can conclude that disabled architects are capable of achieving what able architects can achieve with an extra perspective. On the other hand, on comparing the other three cases, it is obvious that the companies that employed disabled architects succeeded in achieving competitiveness through different methods, including diversity, integrating a wider pool of experiences and perspectives, avoiding legal issues, and improved images. Finally, on comparing the six case studies, it is clear that competitiveness could be achieved through employing the disabled and that disability is not the barrier; however, the extra perspective is the opportunity. Believing in the capability of disabled architects and providing them with the needed facilities are the right ways for companies to achieve competitiveness.

\section{Data analysis}

\subsection{Background about sampling and response rate}

According to the Egyptian Engineers Syndicate, the number of current registered ADFs is 44 . Out of the 44 firms selected for the sample, only 36 firms responded to the questionnaire. This represents an $81 \%$ response rate, which supports the recommendations and the findings of the research. Although not all from among the intended sample responded, the conducted survey still provides valuable and rich data. 


\subsection{Summary of findings}

- Most of the respondents tend to believe that disabled architects are less capable of having a career. This goes back to the discrimination and the stereotyping that Egypt is suffering from. On the other hand, it reflects the importance of the supervision of the government on the activation of the codes concerning their rights of employment and training.

- Most of the respondents tend to believe that the availability of a job is not of a great influence on the disabled person's capabilities, which reflects the importance of training and spreading awareness about disabled people's capabilities and the difference between impairment and disability.

- Furthermore, $52.38 \%$ of the respondents do not even know about the employment codes for the disabled, which thus increases the need for focusing on spreading awareness not only to the employers but also to the disabled themselves to be aware of their rights. Moreover, strict actions must be used against discrimination.

- In addition, $51.43 \%$ of the firms in Egypt do not apply the codes. This is a direct alarm for the government to take stricter actions against companies that do not apply the codes of employment for the disabled.

- The firms do not take any action to avoid any legal issues, as it is not even an area of concern to the government itself.

- Most of the firms do add names of disabled to their employees list without really giving them a real job, giving them small salaries instead.

- A relatively big percentage of employers are not even aware of the codes of employing disabled.

- The barriers that were most commonly selected are the following: "performance on construction site", which could be a real problem for some types of disabilities and could be a neglected problem for other types; "accommodation", which needs specific experience and includes general accommodation and specific accommodations; and "discrimination and bias", which could be a real problem, especially in Egypt, and that was obvious in the responses of employers to the other questions too.

- The majority of the companies are averagely diverse, which means that the employers are aware of the importance of having a diverse organization; the remaining firms do not believe in this and question how diversity can serve the company or be a method of achieving competitiveness.

- It is widely agreed that integrating disabled architects in companies is beneficial, which means that the employers believe in the differences of the disabled.
- It is widely agreed that diversity leads to competitive advantage in the ADFs as it helps in widening the pool of experiences, which serves a larger pool of users.

- The most commonly used factor is diversity, followed by having a larger pool of experience and improved image. Although the chosen factors show more awareness of the importance of having different cultures, backgrounds, abilities, and disabilities, it also proves that there is no governmental supervision on the applications of the legal codes; the factor "legal issues" is ranked the fourth most important factor.

The collected and analyzed data provided an insight to the research as well as serve as a valuable contribution, which will help in developing the framework. This chapter included all the responses that were obtained from the survey questionnaire. The presented data analysis provided valuable data on the study issue. This chapter provided a clarification to the issues related to the study from the employers' and firms' points of view, which not only helps in developing a framework but also in arriving at an in-depth understanding to the problem in Egypt, which empowers the research's aim and objective.

\section{The Integration of Disabled Architects Framework (IDAF)}

\subsection{Definition and rationale}

The Integration of Disabled Architects Framework (hereinafter referred to as "the framework" or the "IDAF") is an innovative tool developed by this research to formulate the integration of disabled architects in ADFs for achieving competitive advantage. It describes the different human resources management aspects that ADFs can follow to facilitate the recruitment, selection, training, and motivation of disabled architects in ADFS. The rationale of the framework stems from the necessity to assist the government in achieving its sustainable development objectives through making efficient use of its human resources.

\subsection{Description of IDAF}

The developed framework consists of the following components (Table 1):

- Practices and policies

- Organizational structure and accommodation

- Recruitment 
- Promotion and advancement opportunities

- Health and safety

- Managerial programs

- Recruitment and selection

- Training and motivation

The IDAF is a unique tool of facilitating the integration process through the following fields.

\subsection{Limitations of IDAF}

The IDAF is designed for the purpose of aiding in the integration of disabled architects in ADFs in Egypt.

The framework may not suit all types of disabilities as it depends on the most common disabilities; on the other hand, there are also a number of disabilities that are easier to deal with without the need for following all the steps included in the framework. In other words, some disabilities such as autism are not considered a real disability or barrier in Egypt; on the other hand, some impairments would not be as hard to deal with as the others: e.g., an architect with talking impairment can perform his/her tasks on site better than a paralyzed architect; however, a paralyzed architect can present his/her work better than an architect with talking impairment.

The functionality and adaptability of IDAF is limited as it depends on government movement toward supervising the usage of the employment codes for the disabled in Egypt, toward the development of ADs specifically and the Egyptian environment in general.

The application of this framework could be considered a long-term plan aiming to improve the competitiveness of ADFs in Egypt, providing job opportunities to disabled architects, utilizing all the wasted human resources in Egypt, and integrating the disabled architects in firms in order to achieve competitiveness. This requires commitment from the Egyptian government to supervise the firms, the firms to follow the law and take the risks of

Tab. 1: The IDAF components.

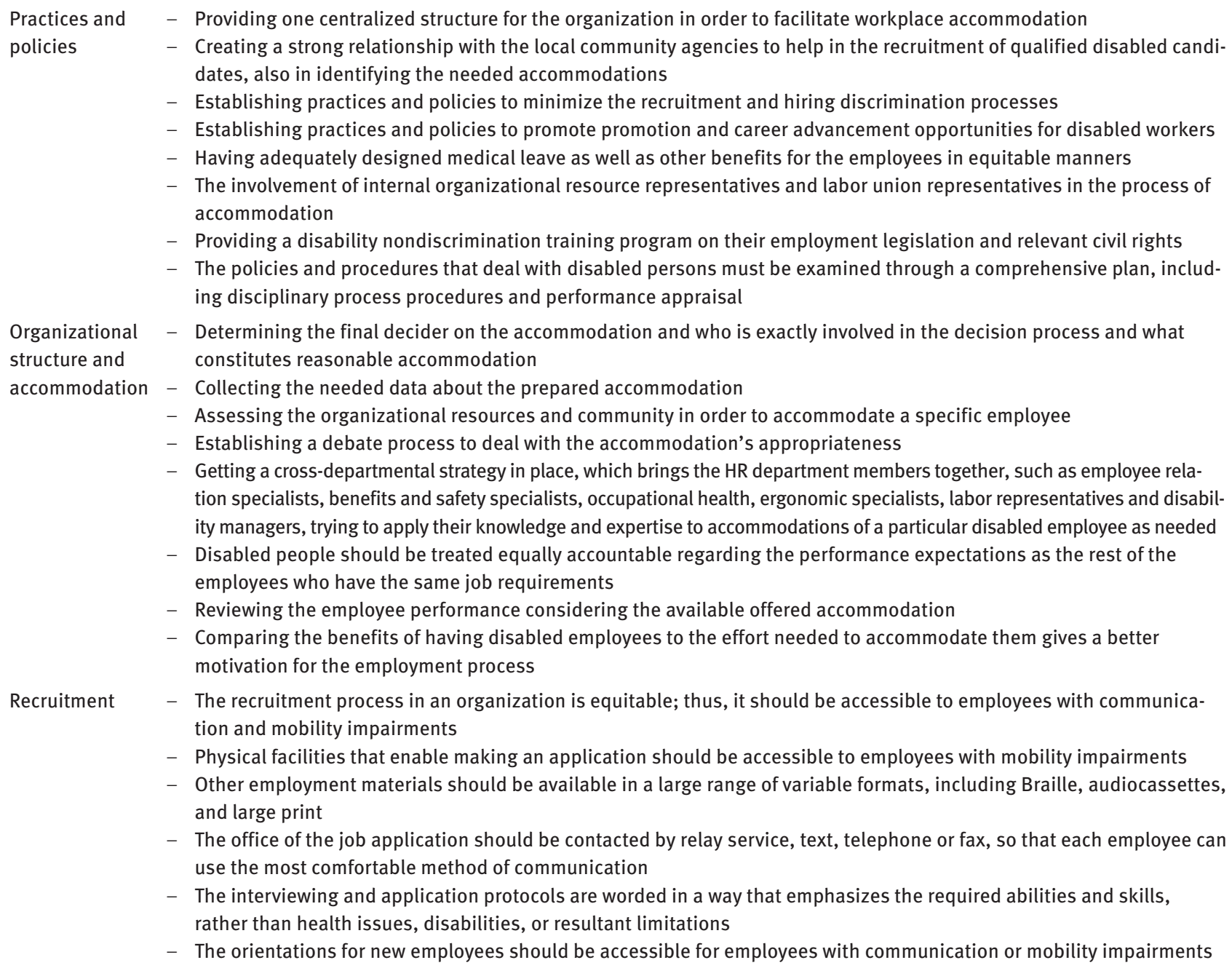
tion specialists, benefits and safety specialists, occupational health, ergonomic specialists, labor representatives and disability managers, trying to apply their knowledge and expertise to accommodations of a particular disabled employee as needed

- Disabled people should be treated equally accountable regarding the performance expectations as the rest of the employees who have the same job requirements

- Reviewing the employee performance considering the available offered accommodation

- Comparing the benefits of having disabled employees to the effort needed to accommodate them gives a better motivation for the employment process

Recruitment - The recruitment process in an organization is equitable; thus, it should be accessible to employees with communication and mobility impairments

- Physical facilities that enable making an application should be accessible to employees with mobility impairments

- Other employment materials should be available in a large range of variable formats, including Braille, audiocassettes, and large print

- The office of the job application should be contacted by relay service, text, telephone or fax, so that each employee can use the most comfortable method of communication

- The interviewing and application protocols are worded in a way that emphasizes the required abilities and skills, rather than health issues, disabilities, or resultant limitations

- The orientations for new employees should be accessible for employees with communication or mobility impairments 
Tab. 1: (Continued)

- Cooperating with aid organizations and rehabilitation agencies to provide an aid in impaired employees' counseling, training, and identifying the appropriate job candidates

- Employers must examine the practices and policies that concern the preemployment testing and screening, as well as the new employees' orientation, in order to make sure that the organization must not screen out disabled applicants

- Using more fair techniques in screening the impaired applicants' forms respecting his/her impairment, taking it into consideration and dealing with it, without neglecting his/her experience or characteristics that are not related to his/ her impairment

- Putting the competitiveness that can be gained by employing a disabled person aside is not a fair evaluation to his/her integration, unless his/her impairment is also ignored

- Dealing with the impaired applicant as an opportunity must be considered in parallel with dealing with him/her as a burden

Promotion and advancement opportunities

Health and safety

Managerial programs

Training
- The promotion opportunities and career advancement are equitably applied to employees with impairments

- Communication about the promotions should be available in an accessible format to employees with impairment concerning communication

- The external career and training opportunities advancement afforded to the employees should be accessible through being held in a physically accessible facility and by showing the needed relevant support for the impaired employees

- Studying the barriers of employment for every impaired person according to his/her impairment, capability, characteristics, the surrounding environment, and the resources, which gives a deeper understanding for dealing with the employee and his/her impairment

- The employee promotion should only be based on his/her performance in the workplace after providing him/her with all his/her needs

- The disabled employee can be the companies' icon of diversity, which can be positioned where it belongs in the companies' structure

- Promoting an impaired employee can be a method of acquiring competitiveness not only through diversity but also through improved image

- The health benefit plans provided to the employees should be equitably available to the impaired employees

- Work-related or employer-provided social activities and recreational facilities should be accessible for employees who deal with cognitive, communication or mobility impairments

- Providing the employees with life, disability, and health benefits

- Giving the employees with impairment special privilege for taking breaks, having fixed working hours and vacations according to their health conditions and the hours they need for rest, taking into consideration that if it does not suit the employees' position, the position may need to be modified

- Giving the employee tasks that he/she has the ability to perform better respecting his/her impairment; e.g., if the employee is paralyzed or uses cranes, it is not preferable to spend most of the working hours on the construction site

- Return-to-work or disability management should focus on early intervention in illness situations or disability to help in maintaining the employee in the workforce or returning him/her in a timely way to work. The methods in which management deals with the prevention of disability or injury, as well as dealing with return to work or disability management situations, have a significant impact on the well-being and health of the workers.

- The related factors should include corporate culture, worker and management safety, and the prevention techniques, as well as the disability management and the company policies

- The disability management program should support the process of accommodation that eventually helps in minimizing workplace disability discrimination

- Recognizing the importance of the confidentiality of medical information, increasing the supervisors' awareness of the process of accommodation, raising acceptance for disabled people in workplace, and creating an accommodative organizational structure

- Training is considered a significant contribution to the effective implementation of policies and practices in the workplace, as well as the implementation of nondiscrimination for disabled in the workplace

- The organization should articulate its commitment to the equitable employment and recruiting of disabled persons, starting from the top level of management.

- Training for creating a zero-discrimination environment toward the disabled

- Supervisory training, including information about disability civil rights legislation requirements

- Supervisory training, including information about preparing the general accommodations for disabled including mobility and communication, as well as preparing individuals' accommodation for a specific disability that may need a particular occupational setting

- Training should also be provided for all supervisors on how to be able to maximize the use of both community resources and internal organizational resources in supporting the disabled

- Trainings should be provided to all organizational members on how to get the best from the disabled employees with the goal of achieving competitiveness, giving them all the confidence, trust, and reliability they need

- The importance of this kind education through trainings should be evaluated and monitored, and this process can take place through measuring the improvement in the coworkers' attitude 
employment, and the disabled architects to put in extra effort to be more profitable than expected.

\section{Research findings and recommendations}

Having reviewed the concept of disabilities and competitive advantage in order to investigate the role of integrating disabled architects toward achieving competitive advantage in ADFs and bearing in mind the developed methodology of literature review, case studies, and survey questionnaire, the research reaches the following findings and recommendations.

\subsection{Research findings}

\subsubsection{Literature review}

The word disability is totally different from the word capability; the capability not only depends on the persons' impairment but on other factors including his/her characteristics, the environment, and the resources, while a disabled person is someone who lacks an opportunity and not someone with impairment. There are many barriers facing the firms employing disabled persons based on the persons' impairment and the facilities available in the firms. Moreover, the disabled in Egypt are marginalized and ignored, and even the codes for employing them are not activated. Finally, disabled integration is a method of achieving competitiveness through diversity, legal issues, improved image, and tax benefits.

\subsubsection{Case studies}

Disabled architects are architects who have an extra perspective and experience; they are not only capable of doing what other architects can achieve, they can also outdistance and exceed the latter's achievements. Disabled employees' integration is an excellent way of creating a diverse environment, and this integration helps not only in widening the pool of experience but also in avoiding legal issues and improving the firms' image.

\subsubsection{Survey questionnaire}

Disabled architects are actually underestimated by other architectural practitioners as most of the architectural practitioners believe that the availability of appropriate opportunity is not even related to the persons' capability. On the other hand, the codes for employing the disabled are not even familiar to half of the architectural practitioners; about half of the Egyptian ADFs do not apply the codes for employing disabled architects, and most of them do not take any actions to hide these illegal activities. Integration of the disabled is widely believed to be a method of achieving competitiveness mainly through diversity; however, most of the Egyptian ADFs have an averagely diverse community. Finally, among all the barriers, accommodation is one of the most highlighted barriers.

\subsection{Recommendations}

\subsubsection{Recommendations to the Government}

- The Egyptian architectural firms need to be supervised thoroughly as the legal issues concerning employing disabled architects are totally ignored.

- Awareness should be raised among Egyptian citizens to create a zero-discrimination environment.

- Stricter actions should be taken against firms that do not apply the codes of employment for the disabled.

- The Government should obligate the firms to provide the impaired employees with all the needed facilities and trainings.

- It would be more motivating if there are tax benefits for the firms that actually employ the disabled.

- Sudden governmental visits are required to make sure that the firms are actually employing disabled architects and that their names are just added to the employment list.

\subsubsection{Recommendations to the disabled}

- Disabled have legal rights that most of them ignore, and knowing them is the starting point of fighting for their rights.

- Disabled could raise awareness about their capabilities by starting to work individually or in groups to show the community they are living in how special and capable they are.

\subsubsection{Recommendations to ADFs}

- Giving disabled an equal opportunity is a legal right.

- Providing them with all the accommodations and facilities is needed before evaluating their performance. 
- Adding their names on the employees list without actually employing them is completely unethical.

- Integrating disabled architects in the firms is a successful method of achieving competitiveness.

- Developing training programs for all the members in the firm to raise awareness about the way of treating disabled coworkers as well as appreciate his/her capability and rights will help all the members and will help in creating a more friendly and zero-discrimination environment in the firm.

\section{Conclusion}

Disability is defended and respected by all employers and is defined as the lack of opportunity rather than being defined as the presence of an impairment; however, the disabled in Egypt are marginalized and even the quota of employing 5\% disabled in each organization is not activated. Furthermore, the architectural regulations for practicing the job in Egypt do not include any regulation that bans the disabled from having a career, yet they are unemployed. Although the employers react with a positive attitude toward disabled persons, this attitude is negatively applied when it comes to employing them due to a lot of barriers. The competitiveness presence in a company has a number of advantages and disadvantages and is based on different methods; one of them is diversity in the workplace. Through analysis and comparison of the case studies, it is clear that the achievement of competitiveness is based on providing disabled architects with the needed facilities more than being based on his/her disability. Finally, IDAF has been developed to facilitate the process of integrating disabled architects in ADFs as an approach for achieving competitive advantage.

\section{References}

Barnartt, S. N. (2010). Disability as a Fluid State. Emerald Group Publishing Limited, Washington.

Brown, S. E. (2002). Institute of disability culture. Disabilities Studies Quarterly, pp. 34-50.
Crow, K. L. (2008). Four types of disabilities. Tech Trends, pp. 51-55. Egyptian Engineers Syndicate. 2015. Organizational Practice Regulations. Egyptian Engineers Syndicate, Cairo.

Ehmke, C. (2008). The Strategies of Competitive Advantages, s.l.: Department of Agricultural and Applied Economics.

El Sayed, O. L. E. (2013). Engineering and Engineering Education in Egypt. IEEE Technology and Society, Cairo.

Elshami, N. (2012). Muftah. [Online] Available at http://muftah.org/ people-with-disabilities-in-egypt-overlooked-and-underestimated/\#.VifSnn4rLIU on 12 May, 2017.

Graham, P. L. (2014). Gallaudet University. [Online] Available at https://www.gallaudet.edu/150/celebrate/visionary-leaders/ olof-hanson.html on 12 May, 2017.

Joseph, C. (2015). The advantages of hiring disabled people in a company. Hearst Newspaper, pp. 200-212.

Kaye, H. S., Jans, L., \& Jones, E. C. (2011). Why don’t employers hire and retain workers with disabilities. Journal of Occupational Rehabilitation, 21(4), pp. 526-536.

Ministry of Planning. (2016). Sustainable Development Strategy: Egypt Vision 2030. [Online] Available at http://www.mop.gov. eg/Vision4.pdf on 12 March, 2017.

Mitra, S. (2006). The capability approach and disability. Journal of Disabilities Policy Studies, 16(4), pp. 236-247.

Olson, S. (2004). An Architect with Disabilities Champions Public Accessibility for all. [Online] Available at http://www.seattlepi. com/ae/article/An-architect-with-disabilities-champions-public-1138740.php on 10 May, 2017.

Prato, A. (2013). Chris Downey: My Life as a Blind Architect in San Francisco. [Online] Available at http://ideas.ted.com/my-citylife-as-a-blind-architect-in-san-francisco/ on 5 February, 2016.

Riley, J. (2015). Competitive Advantage. [Online] Available at http:// www.tutor2u.net/business/reference/competitive-advantage on 12 May, 2016.

Sen, A. (2005). Commodities and Capabilities. Elsevier, Amesterdam.

Sharaf, Y., \& Othman, A. A. E. (2015). Workplace Women Diversity as a Strategic Approach for Achieving Competitive Advantage in Egyptian Architectural Design Firms. In: International Conference on Industry Academia Collaboration, 6-8 April 2015, Cairo, Egypt. Online Available at https://www.researchgate. net/profile/Ayman_Othman.

WHO. (2014). Disabilities and Rehabilitation. World Health Organization, United Nations. 